\title{
The jogo-go-go must go on - a construção de uma interpelação trágica-farsesca na performance urbana contemporânea: 0 exemplo Hasard do Erro Grupo
}

\author{
The jogo-go-go must go on - the construction of a tragic-farsical \\ interpelation in contemporary urban performance: the example of \\ Hasard performed by Erro Grupo
}

Stephan Arnulf Baumgärtel ${ }^{1}$

Mayana Marengo²

\begin{abstract}
Resumo
O presente trabalho analisa as configurações do papel do espectador criadas pelas estratégias do grupo teatral-performativo ERRO, que insere seu jogo performativo Hasard no cotidiano urbano. Partimos da hipótese de que o ERRO Grupo tematiza com suas ações uma crise profunda da democracia e das relações sociais frente à hegemonia das relações econômicas capitalistas. Vemos essa crise principalmente no modo como Hasard qualifica a participação do espectador no evento cênico. A configuração da participação do espectador oscila paradoxalmente entre ser a razão de existir do jogo cênico e uma função efetivamente anulada para que o jogo aconteça e continue. Longe de ser uma fraqueza da proposta, ela constitui a contradição mais significativa da montagem. Esta oscilação leva o espectador contemporâneo a vivenciar o que pode ser chamado uma experiência política de dimensões trágico-farsescas.
\end{abstract}

Palavras-Chave: ERRO Grupo, Políticas do olhar, Recepção teatral, Teatro performativo.

\begin{abstract}
The following paper analyses the performance strategies used by Brazilian theater and performance group ERRO GRUPO in their intervention Hasard, to interpelate the spectators and to place them critically both within the theatrical game as well as the urban environment. We part form the hypothesis that ERRO Group's interventions pick as their central theme the profound crisis of democracy and its social relations in face of the hegemony of economic relations in a capitalist society. We perceive this link between theatrical and social crisis especially in the way how Hasard qualifies the participation of the spectators. The role of the spectators is modeled as to oscilate paradoxically between the raisond'etre of the game and a function effectively rendered unconsequential for the game to happen and to continue. This oscilation is a significant contradiction, for it takes the spectator to experience and possibly live through what can be called a political experience of tragic-farsical dimensions.
\end{abstract}

Keywords: ERRO Grupo, Performative theatre, Politics of perception, Reception.

1 Professor adjunto do curso de Artes Cênicas e do Programa de Pós-graduação em Teatro - Universidade do Estado de Santa Catarina (UDESC). 


\section{O espaço cênico e as sobreposições do real ao ficcional: propostas para uma percepção autocrítica do espectador}

No âmbito teatral, ao longo dos últimos dez anos as estratégias de interseccionar a realidade social empírica e a realidade ficcional vêm se tornando uma prática corrente. Isto levou a uma diluição da fronteira entre palco e plateia, o que criou espaços cênicos híbridos, pois ao justapor e entrelaçar a representação ficcional e a ação real performativa ou a representação de uma ficção e a apresentação de elementos documentários, o mundo do palco deixou de ser hegemonicamente ficcional, representação de um outro lugar, e evidenciou-se sua realidade empírica, pertencente ao mundo cotidiano do espectador.

Tentativas desse tipo - formalmente muito diferentes entre si - se manifestam tanto nas diversas práticas teatrais (aconteçam essas práticas em espaços fechados ou abertos) quanto nas diversas publicações que acompanham e estimulam essa tendência performativa. ${ }^{3}$ No contexto do teatro praticado no espaço urbano, essa tendência traduz-se muitas vezes em táticas de fazer o público participar do andamento das ações cênicas, seja na função de figurantes, seja na de atores espontâneos, a fim de posicionar o público em uma relação consciente com sua realidade cênica tanto quanto simbólica.

Se este convite à participação foi pensado nos tempos iniciais destas práticas (durante os anos 60 e 70) como uma tentativa de tornar o espectador mais ativo e consciente de suas possibilidades de ação durante a apresentação teatral, mas também na encenação social da vida cotidiana, os trabalhos construídos a partir do final dos anos 90 começaram a problematizar essa possibilidade emancipadora. Menos entusiastas do que críticos, eles começam a construir seu convite concreto enquanto entrada em um labirinto ou uma expedição, às vezes como estrutura autocontraditória ou double-bind ("(inter)aja espontaneamente", "seja você"); instalam no campo simbólico uma realidade falsa e/ou propõem ficções que se revelam, paulatinamente, como sendo realidades sociais. Os espectadores vêm se encontrando em um espaço entre ficção

3 Ver, entre outras, as publicações de Sanchez (2007), Soler (2010), Deck e Sieburg (2008), Tiedemann e Raddatz (2007), Cornago (2006), bem como trabalhos teatrais de diretores e grupos, tais como René Pollesch, Rimini Protokoll, Gob Squad.

4 A noção de double-bind foi desenvolvida pelo psicólogo Paul Watzlawick, junto com seus colegas do Mental Research Institute de Palo Alto (Califórnia/EUA). Caracteriza-se por uma comunicação em que o proponente confronta seu locutor com uma expectativa contraditória, impossível de ser respondida sem autocondenação, de modo que qualquer resposta direta leva o locutor implicitamente a "assumir um erro". 
e realidade, entre liberdade e regulamentação, entre voyeur e coagente. Suas coordenadas para separar ambas as esferas e definir sua relação ficam temporariamente suspensas, o que implica que também seu olhar está se desestabilizando.

Auto-percepção e percepção do outro perdem foco, clareza e transparência, na mesma medida em que elas se evidenciam enquanto problema antropológico e desafio estrutural da obra teatral-performativa. Parece que este teatro desloca o conflito da narrativa (ou do discurso ficcional) para a relação do espectador com a obra; para sua relação com um contexto social que - dada a hibridez do espaço e fazer cênico - ora é o acontecimento teatral, ora é a vida social empírica no qual este acontecimento se manifesta. ${ }^{5}$

Acreditamos que essas estratégias, por um lado, fazem parte de uma crise do teatro enquanto espaço simbólico autônomo, enquanto representação de uma ficção empiricamente ausente que ganharia relevância para a vida dos espectadores unicamente por meio da atividade interpretativa hermenêutica. Por outro lado, também indicam a crise das diferentes tentativas de fundir o espaço empírico e o espaço artístico, de transformar as práticas sociais por meio das práticas artísticas, ou mais especificamente de declarar as práticas artísticas como sendo criticamente sociais. Advertem, a nosso ver, sobre uma crise tanto do teatro representacional quanto da ação performativa. Se o primeiro tem dificuldades de criar um encontro impactante com o espectador em sua vida social, a última tem dificuldades de levar o espectador para além do momento de choque, de modo a alcançar uma densidade e complexidade simbólica que the confira um impacto mais profundo

Perante esta situação, podemos compreender esta proposta de criar espaços e vivências híbridas como uma tentativa contemporânea de assegurar (ou devolver) aos trabalhos artísticos teatrais uma relevância empírica: fazer com que o trabalho artístico esteja simbolicamente em sintonia crítica com a complexidade da vida contemporânea e dessa forma seja potencialmente útil. Como se o potencial do teatro hoje não fosse (predominantemente) a materialização de histórias ficcionais, mas a materialização de relações psicossociais que atravessam a situação teatral, construindo em seus melhores exemplos temáticos uma relação confrontante do particular/individual com o regrado/social. Constroem, principalmente, uma relação do espectador consigo

5 Neste sentido, estamos perante uma concretização da fórmula de Hans-Thies Lehmann (2009) de que no teatro pós-dramático se manifesta uma "política da percepção", uma "interrogação da percepção" a partir e em relação à construção de narrativas e práticas fundadoras do espaço público-político. 
mesmo e com seu próprio olhar, fazendo-o interrogar sua posição em relação às ações apresentadas e, indiretamente, à vida social que o rodeia.

Deste modo, podemos ler os elementos performativos oferecidos aos espectadores também como um procedimento de reinstaurar a dimensão dramática do teatro: instalar o conflito dramático na relação entre espectadores e o jogo cênico; instalá-lo nos motivos pelos quais querem participar e nos modos como eles podem efetivamente participar das ações cênicas propostas.

Entendemos que a configuração do olhar ${ }^{6}$ do "espectador" por meio do jogo cênico (ou seja, a configuração da recepção) surge como uma modalidade contemporânea do jogo dramático. Quais são as regras deste jogo em Hasard? Qual é a dimensão simbólica que o jogo cênico nos apresenta por meio desta configuração da relação espectador-ação cênica? Queremos levantar a tese de que a participação do público em Hasard é configurada de tal modo a criar um double-bind entre ser estimulado e simultaneamente impossibilitado de participar efetivamente. $O$ efeito pretendido nos parece ser de problematizar as diferentes formas de participação social oferecidas hoje, da manifestação de um coletivo na rua até o ritual da eleição. A inclusão do espectador nas ações performativas do trabalho faz com que essa problematização seja vivenciada pelo espectador numa trajetória em que ele próprio oscila entre o que podemos definir como uma posição de um herói virtual e a de um seguidor coadjuvante, criando assim uma sensação trágica, na medida em que o espectador percebe que sua vontade de participação o levava a aceitar ou até ficar cego perante as armadilhas que tornam a participação não efetiva.

\section{O realismo performativo de Hasard: criar um jogo da perda como efeito de real}

"Hasard ocupa um quarteirão da cidade, com quatro cenas simultâneas que, ao longo da peça, contaminam umas às outras, utilizando a aleatoriedade e a simultaneidade como operação." ${ }^{7}$ Trata-se de um espaço cênico em quadrado entrelaçando ações em um roteiro, que é ao mesmo tempo rigidamente definido e aberto nos detaIhes, fragmentado de modo a não oferecer uma visão totalizante. Quatro dispositivos de jogos que se expõem ao espectador, convidam-no com mais ou menos intensidade

6 O Erro Grupo fala em "acompanhar a obra", não só porque a apresentação realiza um itinerário, mas também porque se oferece uma participação do espectador que possivelmente ultrapassa a distância do olhar e do observar. 7 ERRO GRUPO. Hasard. Uma quadra, quatro situações simultâneas, escolha sua posição. DVD. Florianópolis, 2012. 0:02. 
a acompanhar e "participar da brincadeira". Propostas de participar em ações performativas, em operações concretas cujo status lúdico é incerto: treinamento policial da tropa de choque, ligar para números de celulares, apresentar-se em um karaokê e jogar cartas, discutir com os atores e espectadores sobre as cenas ocorridas.

Os espectadores se veem também perante quatro personagens que conduzem situações cujo foco oscila entre a ficção e ação cênica concreta: uma jornalista, um mestre de brincadeiras e jogos, um empregado de uma empresa de vigilância, uma funcionária de uma instituição pública. Também aparecem em cena mais três figuras coadjuvantes, que também oscilam entre personificação e performatividade. Eles levam as quatro cenas pelas ruas até encontrarem-se na cena final no mesmo lugar, formando outro quadrado, ${ }^{8}$ finalizando o trabalho com uma ação que (con)funde o real e o ficcional e que é enganosamente determinada pelo maior número de cartas do mesmo naipe: por mais que o final pareça abrir-se para a aleatoriedade, não se abre para a vontade racional e consciente do público. De fato, a cena final, nas cinco versões que parecem existir para este momento, é definida pelo roteiro e/ou pelo acaso, mas não pelo público. ${ }^{9}$ Em outras palavras: Hasard submete a vontade participativa do público às decisões dos atores-performers e às imponderabilidades do acaso, mas também levanta a questão de até que ponto ambos são construídos pela vontade e pelo controle onipresente da direção, e de quais seriam as possibilidades de transgredi-la. ${ }^{10} \mathrm{O}$ trabalho problematiza em sua estrutura performativa essa submissão, sem tornar o problema objeto do discurso verbal proferido pelos atores-performers.

O espectador que procura dados para interpretar hermeneuticamente os acontecimentos sempre se encontra numa situação precária: numa deficiência de dados perante acontecimentos que parecem ser ao mesmo tempo aleatórios e inflexíveis, a não ser que se decida que exatamente esta deficiência e rigidez é constitutiva para o funcionamento e a comunicação da peça com seu público. A estrutura da peça deixa

\footnotetext{
8 A racionalidade cartesiana desta estrutura, entretanto, é quebrada por uma performer que fica fora deste quadrado falando e rezando em voz semialta slogans do cristianismo carismático. Na ocasião em que participei da apresentação, contudo, a maioria do público não prestou atenção ou não reagiu à sua presença.

9 A participação do púbico é puramente formal, como agente que reúne as cartas ("os votos"), sem que tenha consciência disso e sem que possa escolher ou redefinir as consequências reais da entrega das cartas. Portanto, não precisa ter igualdade formal (um espectador - uma carta) no momento da entrega. Interessantíssimos os finais nos quais os espectadores são levados a transgredir essa participação formal e apostar os próprios pertences. Transgressão que coloca metaforicamente em cheque o modelo representativo e articula uma vontade de participação direta no processo de criação de vontades políticas. Não ser mais jogador, mas produtor de outra realidade.
} 
tanto o espectador tradicional (que busca contemplar personagens com vontades antagónicas que executam uma ação ficcional significativa) quanto o espectador "interativo" (que busca participar da peça ao interagir com os atores-performers dinamizando o círculo de feedback e assegurando sua posição de coprodutor do significado da apresentação) bastante perdidos. Esta sensação fundamenta, entre outras reflexões, a intenção artística do trabalho: "É inerente ao Hasard a escolha de uma rua para acompanhar a obra - ou parte dela. É impossível assisti-lo na integra de uma só vez. Não perca a sua oportunidade de perder, escolha sua posição."11

Ao invés de afirmar que observar e participar neste jogo cênico implica em passar por uma experiência de liberdade (seja por meio da inserção na ficção artística, seja por meio de um ato interpretativo emancipador), a configuração das ações nos faz sentir que estamos entrando num campo que não só provoca, mas sobretudo restringe nossa liberdade. Pior ainda: que nos propõe uma liberdade (por exemplo, de andar livremente entre as quatro ruas, participar em uma ação performativa ou não, interpretar ou não os acontecimentos enquanto simbólicos), para deixar claro que essa liberdade não faz muito diferença para o andamento da obra ou para a construção de um possível sentido para ela. $O$ baralho de cartas repete em sua embalagem uma frase que podemos adaptar a esta problemática: "Não é possível dizer onde acaba o jogo [a liberdade] e onde começa o falso-jogo [a pseudo-liberdade]."

Mas o tema da perda enquanto fracasso e frustração do olhar (hermenêutico) do espectador, os efeitos da fragmentação do saber sobre o espectador e o poder do acaso sobre a trajetória cênica não estabelecem apenas uma indagação crítica meta-performativa sobre as modalidades de recepção, a validez e a necessidade de um espectador participativo ativo (noções tão caras para trabalhos teatrais nos espaços públicos). A temática da perda não diz respeito só à perda da transparência da obra e da possibilidade de uma posição panóptica dos observadores. A palavra perda é usada pelo grupo para construir um paralelismo entre a peça artística (sua temática e estrutura) e a vida social empírica.

O baralho de cartas, intitulado 54 notas para agir, cada uma com seus slogans, reflexões e afirmações que relacionam as práticas de jogo com 4 grandes temas da convivência humana (poder/subversão, amor/felicidade, dinheiro/capital, segurança/ proteção), possui dois coringas. Em um deles, afirma-se, por exemplo, que

11 ERRO GRUPO. Hasard. Uma quadra, quatro situações simultâneas, escolha sua posição. DVD. Florianópolis, 2012. 0:12 
ninguém para a grande roda e já estamos perdendo algo. Não é possível estarmos em todos os lugares ao mesmo tempo. [...] Se perder ou ganhar, não saia. O pavor em perder nos faz fantasiar que não perderemos sozinhos; que perderemos todos juntos. Perdemos a todo instante a possibilidade de vivenciarmos outra coisa. [...] Nosso conforto está sempre relacionado ao sofrimento de alguém, quem não joga, também participa. Uma vez no jogo, joga-se até o fim.

Juntos com as ações performativas (a oferta de jogar cartas, a jornalista que faz enquetes na rua, a funcionária que inspeciona os bueiros na rua), sugere-se a impressão de que o jogo cênico e sua participação nele já é o jogo do qual se fala nas cartas, com todas suas incertezas, e de que o jogo mencionado nas cartas é o jogo socioeconômico de nosso dia a dia empírico. Desse jogo empírico, de fato, participamos incessantemente, embora a questão mais importante talvez seja em quais posições participamos dele e como podemos nos tornar produtores e não apenas executores desse tipo de jogo.

O paralelismo sugerido entre jogo ficcional e empírico permite entender o sentido duplo (e contraditório) de frases como "uma vez no jogo, joga-se até o fim". Ele elucida outra característica estrutural que permeia a construção do espetáculo e constrói quase algo como a espinha-dorsal de sua lógica narrativa: a força do factoide, da opinião que se apresenta como fato; do fato que busca impor uma ação interpelativa. É especialmente a construção dessa fusão enquanto double-bind cênico que permite apresentar a realidade multifacetada enquanto estrutura fechada e inabalável, independente da nossa vontade e de nossos desejos; afirmar de modo crível, pois consistente no interior da forma artística, a força do comportamento regulamentado em detrimento de nossa capacidade de agir, de fazer e criar diferenças e transformações. Chama a atenção o fato de que os performers pronunciam constantemente (e do ponto de vista performativo o fazem de modo convincente) estes juízos terminantes acerca do caráter do jogo, embora uma das características do jogo seja também a impossibilidade de finalizá-lo e sair dele. Eis um dos double-binds formulados com a expressão "Uma vez no jogo, joga-se até o fim": a tentativa de terminar o jogo será somente outro modo de jogá-lo. Dada a situação teatral performativa, a frase também reprime possibilidades de discutir qualitativamente os modos de jogar em prol da mensagem performativa: joguem até o fim (sem que esteja claro quando chegar a ele ou em que consiste esse fim).

Tanto no baralho entregue aos espectadores-acompanhantes, quanto nos trechos textuais ditos pelos atores-performers, sobrepõe-se o caráter prescritivo e performativo ao caráter descritivo das frases. Disso resulta uma tensão acerca do caráter verídico 
de afirmações como as mencionadas acima. Do ponto de vista ético, pode-se levantar a questão do deboche dos artistas com o público crédulo ou ingenuamente participativo, mas antes apresenta-se uma estratégia de construir uma estética de impactos e uma recepção sempre em dúvida sobre o significado e o sentido das ações.

O formato do espetáculo investe bastante energia para nos convencer de que não só a realidade de seu jogo, mas a realidade a nossa volta segue este caráter prescritivo. Aproveitando uma ideia de Roland Barthes (1972, p.35-44) de que a própria escrita em seu funcionamento produz um tipo de realismo e um "efeito de real", podemos dizer que esta dominância da dimensão ilocucionária nas frases enunciadas tem o efeito perlocucionário de produzir um "efeito de real" como impacto básico da proposta de jogar Hasard. ${ }^{12}$ Procura-se criar na percepção do espectador-participante uma dominância do real do jogo, fundada no caráter mais performativo que descritivo ou representacional das afirmações artísticas sobre o mundo do jogo.

Vemos como o trabalho nos apresenta uma representação performativa da realidade social como um jogo no qual estamos todos individualmente inseridos sem poder alterar as regras, influenciar em seu andamento; em resumo, sem poder participar efetivamente dele, apesar de ser constantemente convidado pelo brilho retórico dos atores (e dos discursos sociais) a fazer exatamente isso. Isso é possível pelo motivo objetivo que somos nós, enquanto um todo - povo, eleitores, jogadores - que o criamos e mantemos. Esta tensão podemos ler claramente como metáfora dos dilemas da participação política. O convite ao público para participar no espetáculo de um modo que confronte o espectador com a ineficácia desta participação, com seu caráter de ser uma ação controlada, com a indiferença dos atores-performers, possui sua motivação - a nosso ver - no interesse em tornar a participação um problema palpável para o espectador. A fusão entre realidade e ficção, a sobreposição do elocutivo ao descritivo, preparam uma estrutura dramatúrgica cujo "efeito de real" faz com que o double-bind ("jogue sua impossibilidade de jogar", "participe ineficazmente") inscrito neste convite possua consistência estrutural-cênica.

O grupo arrisca o tédio e a frustração por parte do espectador, para poder problematizar, de modo estrutural e implícito, o papel do espectador no jogo cênico do teatro

\footnotetext{
12 A terminologia de locutivo, ilocutivo e perlocutivo foi criada pelos filósofos da linguagem J.L. Austin e J. Searle, para diferenciar dimensões básicas da enunciação verbal: o ato locutivo seria a comunicação de uma informação ou enunciado; ilocutivo seria a dimensão do ato de fala que expressa a intenção do falante, enquanto perlocutivo se refere à dimensão de criar um efeito no interlocutor.
} 
na rua hoje, bem como a relação destes espectadores com o lugar, o tempo e os outros espectadores enquanto cidadãos que se encontram em um espaço público. Este "efeito de real" coloca em jogo a suposta liberdade do espectador (ou observador ou simplesmente acompanhante da obra) em sua percepção do espetáculo e participação nele, para provocar a sua capacidade e vontade de testar os limites de uma perda de liberdade. ${ }^{13}$ No que segue, queremos apresentar e discutir algumas dessas táticas provocadoras e seus vetores de interpelação do espectador.

\section{A participação paradoxal dos espectadores em Hasard}

Nenhuma recepção ou declaração específica anuncia o início do trabalho cênico dos atores-performers da companhia. Eles chegam na rua e começam com seu trabalho: montar as mesas de jogo e o aparelho do Karaokê, abrir e inspecionar os bueiros da rua, entrevistar transeuntes para um programa de TV, posicionar-se como vigilantes em uma entrada para uma casa. Somente o modo como se realizam algumas dessas atividades pode dar pistas de que não se trata de um simples procedimento cotidiano: uma determinação exagerada, ausência de logotipos, uma indiferença com os comentários e interferências das pessoas. De fato, muitas pessoas confundem os atores com funcionários de diferentes empresas reais ou com vendedores de rua que (estranhamente) propõem diferentes entretenimentos mas não usam essa proposta para vender algum produto. $\mathrm{O}$ público pode circular livremente, pode interagir verbalmente com os atores-performers, sem que isso altere fundamentalmente o andar das ações. ${ }^{14} \mathrm{~A}$ fusão de ações predominantemente representacionais e outras predominantemente performativas produz uma série de momentos cênicos interessantes: o jogo de cartas com as discussões sobre as regras pressupostas do jogo e a importância da vontade de jogar; um treinamento policial no qual os transeuntes-espectadores assumiram a

13 Jan Deck, ao introduzir uma coletânea de ensaios sobre as diferentes funções do espectador no teatro contemporâneo, define - na esteira de Hans-Thies Lehmann - como projeto deste teatro uma política da percepção como projeto de testar a liberdade e eficácia não necessariamente do olhar do espectador, mas do fazer artístico: "Trata-se, antes, de liberar o assistir das amarrações de um 'sentido' objetivo. [...] Um teatro que tematiza o processo da percepção e os limites da participação do espectador, além de relações objetivas de sentido, de esclarecimento político ou de valores universais, alcança seu próprio grau de liberdade. Remete ao fragmentário de subjetividade e aos limites de participação social, mas também sempre volta a por em jogo estes limites." (Jan Deck: Zur Einleitung. In: Jan Deck \& Angelika Sieburg. Paradoxien des Zuschauens. Die Rolle des Publikums im zeitgenössischen Theater. Bielefeld: transkript, 2008. p.17-18)

14 Elas podem obviamente variar entre as diferentes apresentações, mas essa variação não altera o significado do conjunto das ações no jogo. Seria interessante pesquisar entre as pessoas que assistiram/participaram diversas vezes da apresentação como elas receberam e interpretaram essa variedade. 
função dos policiais em treinamento; entrevistas da jornalista com membros do público sobre o que eles quereriam oferecer para um leilão; o recolhimento de testemunhas de uma briga criada na rua; apostas para uma luta de boxe, etc.

Entretanto, nenhuma dessas participações foi aberta ao público para alterar a dramaturgia do espetáculo (e assim "fazer diferença", tanto no nível ficcional quanto real). ${ }^{15}$ Quando se manifestaram as testemunhas da briga na rua ("ele bateu sim"), a jornalista declara em alto tom que "ele não bateu" e manda o espetáculo seguir seu curso. O convite a participar no Karaokê pode ser realizado de modos diferentes, mas a atividade é completamente fechada em si, selada contra o restante das ações. Além disso, as entrevistas gravadas são falsas e não serão nem comunicadas nem discutidas posteriormente com o público: convites para seus 15 minutos de fama que resultam em 15 minutos de sua vida perdidos, se esse foi seu propósito. $O$ impacto da ação se limita ao momento em que está sendo realizado. Trata-se de momentos que produzem um material possivelmente de auto-percepção, mas, principalmente, temático-simbólico sobre o papel do espectador e as estratégias de diversos poderes em estimular a participação e garantir seus limites, sem que esse nível temático seja tematizado explicitamente.

O convite a participar do espetáculo é feito de modo a propor aos espectadores um papel de protagonista e de produtor cênico, enquanto o uso da situação na sequência das ações performativas deixa claro para eles que não passam de executores de um roteiro. Deste modo, instala-se uma dúvida acerca do valor da própria participação. É impossível cumprir plenamente a proposta, como também é impossível não segui-la, pois "quem não joga, também participa do jogo." Esta tensão, que definimos como o double-bind do espectador, é a configuração fundamental que o jogo cênico propõe para a recepção do espetáculo. Os espectadores podem decidir se querem participar, entrar nas regras do jogo, mas essas são colocadas em cena de modo que o jogo continue seu funcionamento sem que a participação possa alterá-las: o treinamento acaba sem que se altere o valor dramático da situação. As caminhadas pelas quatro ruas não criam situações de conflito ou confronto; a aposta na luta de boxe não implica em prêmio para os apostadores, como a premiação ficcional tampouco parece intervir na dramaturgia do enredo ficcional;

150 momento mais interessante neste ponto é o momento final, quanto o público se posiciona de várias formas em relação ao trabalho. O que é possível ao público, e isso é uma enorme qualidade do trabalho, é posicionar-se diretamente enquanto conjunto, ou seja, enquanto massa, perante as autoridades institucionalizadas, como, por exemplo, na ocasião de uma apresentação em Curitiba em abril de 2013, na qual o público defendeu o trabalho e seus atores da intervenção da polícia. 
a análise de uma cena de crime e o levantamento de provas não decidirá nada. Ou seja, o formalismo da participação evidencia (ou no mínimo problematiza) implicitamente uma visão niilista acerca deste modo de participação, mas também levanta a questão política sobre até que ponto a participação em ações "cênicas" ou coreografadas (como manifestações) não impede os espectadores-transeuntes (os manifestantes) de intervir de forma eficiente nas configurações cênicas (políticas) - pois eles acreditam que já fizeram alguma coisa ao simplesmente marcarem presença.

Quando o público insistia em fazer a diferença ao nível da realidade, o fazia sem perceber o caráter construído e dirigido das cenas. A briga entre o mestre do jogo de cartas e a jornalista suscitou em vários momentos uma reação de transeuntes-espectadores querendo defender a mulher das agressões do homem. A função nos parece ser menos de introduzir um efeito de confusão do real e do ficcional, do representacional e do performativo, e mais de evidenciar até que ponto na percepção dos espectadores-transeuntes comuns, esta confusão já está instalada, de modo a vivermos quase em mundos ilusórios sem percebê-lo. Nosso engano, que evidencia a decisão dos espectadores de participar de modo limitado (enquanto comentarista guiado pelos atores) ou deslocado de seu contexto adequado, revela-se como sendo duplo: que haja uma realidade palpável e confiável neste jogo de aparências poderosas e que haja uma possibilidade de participar de modo a criar uma diferença nas regras do jogo.

Mais interessantes, e potencialmente mais ricas, nos parecem as decisões possíveis para intervir no jogo cênico concreto num nível mais simbólico do que real: desviar o jogo de cartas da própria atividade para a discussão de suas regras e objetivos e as próprias chances de tornar-se um vencedor; simular um roubo do cofre do dinheiro público para iniciar uma discussão entre os transeuntes sobre seu uso.

Ouvimos dos atores repetidamente: "O cofre é público, senhor! O cofre é público, senhor! O cofre é seu, meu doutor! O cofre é nosso, meu doutor!" Nessa citação, o jogo ficcional entre senhor e criado oferece uma discussão do significado das palavras público, seu, nosso. Em nível performativo, essa discussão pode ser interpretada e recebida como um convite ao espectador de se colocar no mesmo nível dos atores-performers; de entrar no jogo e discutir com eles, talvez por meio de gritos táticos dos espectadores, tornando a discussão ficcional uma discussão cívica real. Talvez com o resultado desencorajador de que essas intervenções verbais não alteram o andamento da ação ficcional, o que não constitui necessariamente uma fraqueza dramatúrgica do 
trabalho, mas seu ponto de partida para realizar uma análise crítica da participação cívica no jogo social real.

Percebemos que pouquíssimos espectadores queriam assumir um tipo de participação ativa, de tornarem-se produtores da cena por um curto tempo, o que no fundo envolvia discutirem os fundamentos do próprio jogo cênico dentro do contexto criado por ele. Os espectadores não queriam assumir o papel de atores-performers perante o público e os atores-performers "reais", talvez porque esses últimos fossem vistos como figuras autorizadas ou "donos" das ações cênicas.

Portanto, perguntamos: para onde esta participação poderia ter levado os espectadores e o trabalho cênico? O espetáculo nos causou muita vontade de roubar o cofre com - assim se disse - o dinheiro público. Num momento não-vigiado, Mayana pegou o cofre e se afastou, mas logo percebeu que com este ato o problema não seria resolvido, mas somente deslocado: dos atores para ela. Além disso, sentiu o peso moral (real e não ficcional) de ter feito um ato ilícito, de ter se apropriado de um bem que não era (somente) dela. Ao invés de tornar a situação pública ("o cofre está aqui, vamos fazer o quê?") em nível performativo cívico, bateu um medo e ela abandonou o cofre. Logo uma atriz-performer o pegou e o reincorporou no jogo cênico do grupo.

Aqui surgiu, por um momento, a possibilidade de uma "cena de aprendizagem", nos moldes de Brecht, dispensando efetivamente a diferenciação entre atores-espectadores, com possibilidades que teriam provocado os atores-performers e os espectadores a deslocar o percurso dramatúrgico do trabalho, e, nisso, aprofundar coletivamente sua visão sobre a situação tematizada. Neste sentido, também manifestou-se uma possibilidade nova de experimentar algo como uma liberdade simultaneamente reflexiva e ativa: a decisão dos espectadores de expressar sua reflexão sobre a situação por meio da ação cênica é semelhante à decisão do eleitor de participar de um movimento cívico mais espontâneo do que sua participação formalizada nas eleições. Ao mesmo tempo, levanta a questão de se essa participação não seria um estímulo terapêutico temporário para suportar uma situação política engessada num jogo imutável de poderes. Levar o espectador para este lugar de limitações, vivenciando essa situação e refletindo sobre ela, mesmo que seja só implicitamente por meio de sensações corporais irritantes, isso nos parece ser a liberdade que o espetáculo reclama para si mesmo ao confundir em suas ações cênicas representação e performatividade, o impacto e a efemeridade calculados, estimulo e indiferença, ostensão teatral e imitação performativa. 


\section{Considerações finais: do reconhecimento trágico e da repetição farsesca.}

Para terminar, queremos discutir este lugar participativo em termos da repetição histórica enquanto trágico ou farsesco, para levantar algumas questões éticas. Havíamos mostrado que identificarmos como uma regra fundamental do jogo performativo de Hasard a prescrição de que não há como escapar do jogo. Jogo ficcional e jogo real se fundem no discurso e na prática cênicas. Dentro deste jogo, entretanto, há momentos em que as ações convidam espectadores a se aliar a forças formadoras fundamentais; a participar das ofertas de entretenimento, dos rituais e das crenças no amor e num deus todo-poderoso, do controle social pela força policial-militar, da privatização do cofre e de seu dinheiro público, mas também do trabalho jornalístico enquanto força precária do esclarecimento e de um debate público. Para todas essas participações, vale a dúvida de até que ponto a ação proposta é real ou falsa, tal como explicado anteriormente. Por isso, estas participações ou são ineficientes (não alteram nada a nível simbólico ou performativo-real) ou se revelam como parte do problema, uma vez que se mantêm dentro de um jogo de entretenimento com roupas cívicas.

O espetáculo propõe aos espectadores jogar o jogo cênico, fazendo diferença e destacando-se. Essa proposta de modificar o entretenimento meramente passivo se apresenta como forma de evitar "uma perda" (de tempo, de importância) e/ou conseguir um "sucesso" (um reconhecimento, uma aprovação) etc. Mas aos poucos sentimos que nossa participação nesses jogos de fato não muda nada. Antes, perpetua os modos de jogar e portanto termina exatamente com a sensação de que é uma forma de contribuir para que o problema (evitar uma perda e conseguir um sucesso) possa continuar agindo sobre os espectadores. Nossa tentativa de solucionar o impasse é o problema que o produz. Em palavras trágicas, podemos dizer que o espectador é convidado a assumir o papel de herói, mas "acorda" do convite sendo comparsa de um coro impotente - distância entre a importância do voto individual e a percepção de seu impacto real num sistema político surdo e descreditado; presença formal, mas não produtiva, de muitos indivíduos humanos na democracia liberal representacional que de fato define sua produtividade política por sua posição no processo econômico.

Uma vez que essa trajetória acontece repetidamente no espetáculo (pois já é definida de antemão), ela ganha proporções formalistas: o convite configura na primeira vez um caminho trágico, mas que vira um movimento farsesco em sua obsessão de repetição, uma farsa da repetição mecânica. Essa rigidez formal do espetáculo 
confronta o espectador em suas participações não só com sua própria impotência e sua disposição inconsciente de estar conivente ou cúmplice das forças que ameaçam suas expressões de vida própria, como também com uma visão bastante niilista do mundo social como jogo fixo, sem saídas. O controle exercido pelo diretor e seus atores justifica-se apenas por este objetivo. As apostas de Hasard são feitas desde o início por perdedores.

Nessa visão, o perigo que o título Hasard faz aparecer no horizonte referencial simbólico desse jogo performativo, se manifesta como o perigo do niilismo enquanto uma ideologia que justifica a inevitabilidade de uma passividade social que por sua vez se manifesta como (e simultaneamente esconde-se atrás de) uma hiperatividade individual. O conflito, que está em jogo em Hasard, é o confronto de atores e espectadores com esse niilismo e com seu double bind fundante. Esse é composto pelo convite de participar dessa autodestrutiva farsa trágica e pela força de absorção indiferente de sua dramaturgia: "Não perca a oportunidade de perder. Escolha sua posição," como dizem os atores-performers e como anuncia o material impresso e audiovisual do grupo. Nesse double bind, o jogo das palavras engana e simultaneamente revela seu engano: se não há escolha que faça a diferença, há o quê? Diferentes modos de viver a não-escolha da perda?

Um double bind se resolve somente pulando para fora de seus pressupostos comunicativos e usando as estruturas existentes, pois despertar a sensação de querer participar nesse jogo para depois mostrar a futilidade dessa vontade é algo que possui limites quando o objetivo é exercer uma crítica que não seja abstrata. Ela não fornece as bases para uma crítica concreta. Vemos essa dificuldade no ápice do jogo, na cena final em que os atores (na tarde em que assistimos ao trabalho) todos tiram as roupas como ato de "aposta", supostamente resultado do acaso, ou seja, o resultado da "vontade" do jogo de azar. Por mais que essa cena consiga criar uma solidariedade entre atores e espectadores, exposta pelo fato de que vários espectadores também depositam objetos pessoais na pilha de apostas, ela não sai do âmbito auto-derrotista do niilismo e de seu "irmão entusiasmado": o idealismo. O gesto parece transformador, dada a vontade assumida de ficar nu, mas para levar a cena para além do jogo estabelecido, nos parece necessário introduzir outra forma de perda; uma atitude que inverte a lógica da perda por meio de uma transgressão semântica: deslocar o jogo da aposta para a doação e a entrega: ao invés do "eu aposto", dizer "eu doo". 


\section{Referências}

Austin, J.L. How to do things with words. Harvard: Harvard University Press, 1975.

BARTHES, Roland. O efeito de real. In: BARTHES, Roland et al. Literatura e semiologia. Petrópolis: Vozes, 1972.

CORNAGO BERNAL, Oscar. El teatro de acciones o las ficciones reales In: Primer Acto: Cuadernos de investigación teatral, Nº 313, 2006, p.134-144.

DECK, Jan e SIEBURG Angelika. Paradoxien des Zuschauens. Die Rolle des Publikums In Zeitgenössischen Theater. Bielefeld: Transcript, 2008.

LEHMANN, Hans-Thies. Até que ponto o teatro pós-dramático é político. In A Escritura Política no Texto Teatral. Trad. Werner S. Rotschild e Priscila Nascimento. São Paulo: Perspectiva: 2009.

SANCHEZ, José. Practicas de lo real en la escena contemporánea. Barcelona: Visor Libros, 2007.

SOLER, Marcelo. Teatro Documentário: a pedagogia da não-ficção. São Paulo: Hucitec, 2010.

TIEDEMANN, Kathrin e RADDATZ, Frank. Reality Strikes Back. Tage vor dem Bildersturm. Eine Debatte zum Einbruch der Wirklichkeit in den Bühnenraum. Berlin: Theater der Zeit, 2007.

Recebido em 17/01/2014

Aprovado em 31/03/2014

Publicado em 25/06/2014 